\title{
Building a Sustainable Competitive Advantage
}

\author{
Mukesh Srivastava', Andy Franklin², Louis Martinette ${ }^{3}$
}

\begin{abstract}
This paper analyzes cross-industrial best practices and future trends in the context of the contemporary resource based competitive advantage model of the firm. It identifies key managerial levers, tools and systems that can be used to build and sustain a Hi-Technology company's core competences in order to facilitate a more innovative, collaborative 2Ist century corporate culture. A qualitative and quantitative assessment is made of how a firm's leadership, human capital management, organizational culture, design and systems can all collectively merge to create a more dynamic and responsive organization which is far more adept at building unique resources and capabilities, which can then be leveraged to create new market opportunities with high competitive entry barriers.
\end{abstract}

Keywords: competitive advantage; strategy; sustainability.

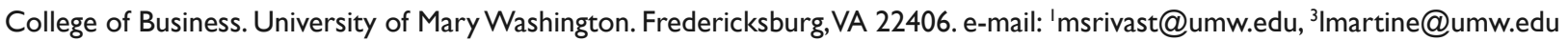
${ }^{2}$ Alltronics, LLC. San Francisco, CA 95050.

ISSN: 07 I8-2724. (http://www.jotmi.org)

Journal of Technology Management \& Innovation (c) Universidad Alberto Hurtado, Facultad de Economía y Negocios. 


\section{Introduction}

To achieve competitive advantage, firms need to constantly focus on the identification of differential product strategies, building or reshaping core competencies, acquiring unique technologies, and accumulation of intellectual property, all of which can all be harnessed to make the company successful in a highly competitive marketplace. Identifying what constitutes a core competence has been a subject of debate in the literature for over 20 years (Prahalad \& Hamel, 1990; Aaker, 1989). This problem has become even more complex with globalization and the growth of the internet, which has given open access to more competitive, environmental, and technological information. One key model that was developed in the 1980's modeled core competencies as unique "resources and capabilities". This was known as the resource based view of the firm (Grant, 1991). Therefore, using this model as a foundation, this research will analyze (i) which key organizational levers influence the competitive advantage(s) of a firm, (ii) propose recommendations as to how 2 Ist century high technology firms can strategically manage their resources and capabilities for a sustained competitive position and (iii) validate and quantify the general perception of the relative importance of these organizational resources and capabilities using a online survey and statistical analysis techniques.

\section{Early Strategy Models}

\section{SWOT Analysis}

One of the early strategy models proposed by Albert Humphrey (SWOT Analysis, n.d.) helped discover the basic elements of competitive advantage. This used very simple concepts and tried to distinguish in the first order between the impact of internal and external factors on a firm's ability to compete. In order to identify potential product and market strategies the SWOT technique forced companies to look systematically at the following aspects of their industry and their firm: Strengths: Attributes of an organization that help to achieve a competitive position; Weaknesses: Attributes of an organization that are harmful to a firm's competitive position; Opportunities: External environmental conditions that help achieve a competitive position; Threats: External environmental conditions which could damage a firm's competitive position.

The aim of a "SWOT" analysis is to identify the key factors that are important to the achievement of the firm's objectives. One of the weaknesses of SWOT analyis is that it can be used to generate a "brainstormed" list of opportunities rather than a thoughtful list of what is strategically important in helping a firm achieve it's objectives.

\section{Porters Five Forces}

A more contemporary analysis model by Porter (1979) brought a greater depth of understanding of a firm's relative competitive position within a given industry, providing analysts with a clear framework for assessing the effect of the external environment on a firm's ability to sustain a competitive advantage. A detailed description of how these various factors interact was discussed by Porter (1979) but summarized here:

- $\quad$ Supplier Power: This relates to how easy it is for suppliers to drive up prices which is driven by the number of suppliers, the uniqueness of their product or service, the strength and control they have over their customers and the cost of switching from one supplier to another.

- Buyer Power: This relates to how easy it is for buyers to drive a firm's prices down. This is driven by the number of buyers in the market, the importance of each individual buyer, the cost to buyers of switching from one product and/or service to those of another firm.

- Competitive Rivalry: This relates to the number and capability of industry competitors. If a firm has many competitors, and they offer equally attractive products and services, then most likely the firm will have little power and influence. If suppliers and buyers do not get a good deal, they will go elsewhere. Alternatively, if no one else can do what your firm does, then you have more competitive strength.

- Threat of Substitution:This is related to the ability of competitors to find new and different ways of imitating a product or service offering. If product or service substitution is viable, then this weakens the competitive power of a firm.

- Threat of New Entry: This is related to the ability of new competitors to enter the market. If it costs little in time or money to enter the market and compete effectively, if there are few economies of scale in place, or if little protection for key technologies, then new competitors can enter a market, weakening an incumbant's position. Strong and durable barriers to entry aid in sustaining a competitive advantage.

Porter's five force model was considered by many to have shortcomings in that it integrates both internal and external factors that allow a firm to identify and sustain its sources of competitive advantage (Pitkethly, 2006) and was is too static to keep pace with the more influential technological progress exhibited in many industries (Five Forces Model, n.d.). Other forces have become significant in the understanding of industry dynamics; e.g. globalization, digitalization, joint ventures, partnerships and de-regulation (Recklies, n.d.) and have all been cited as playing a significant part in a firm's ability to compete. 


\section{Resource Based View of the Firm}

In the 1980-90's a model was proposed by Wernerfelt (1984) and augmented by Barney (1991), which tackled the problem related to the identification of the elements that comprised a firm's competitive advantage. It is known as the Resource Based View of the Firm (Fahy \& Smithee, 1999). This surmised that firms can only create sustained high performance if they have superior "Resources" coupled with the company's "Capabilities" and are constantly protected from migration. According to Gautam, Barney, Muhanna and Ray (2004), Barney (199I) surmised that multiple resources and capabilities form the highest of the competitive entry barriers. This model (Fig. I) shows how resources and capabilities combine to create differentiation that forms the basis of a sustained competitive advantage.

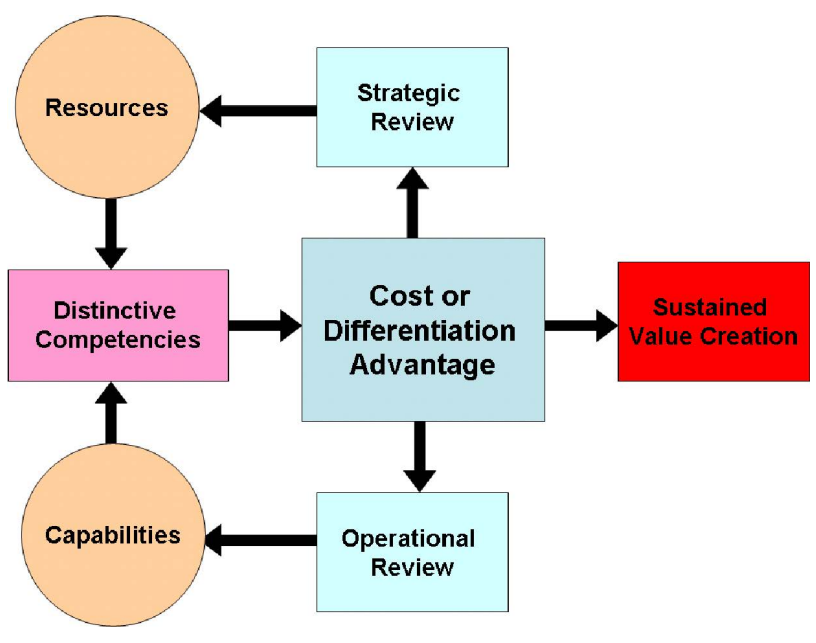

Fig (I) Resource \& Capability Based View of the Firm

In order to create a true cost or differentiation advantage, Barney (I99I) surmised that a firm's resources and capabilities must be:

- Valuable - Resources that implement strategies that will improve the company efficiency or effectiveness that outperforms its competitors or reduces its competitive weaknesses.

- $\quad$ Rare - Resources that are hard to find, unique and cannot found by other companies.

- Imperfectly Imitable - Resources that are very hard to imitate, allowing sustainably because, without huge investment of limited resources, competitors find it difficult to enter the market.

- Non-Substitutable - Resources that have no real equivalence that itself is not rare or imitable.

This list is known as Barney's (199I) "VRIN" resource based view of the firm. Some examples of VRIN resources could be highly cohesive leadership, physical assets, brand equity, installed customer base, company reputation, company values, deep tacit knowledge, strong patents, trademarks, copyrights, trade secrets, unique technologies, strong legal representation and inter/intra company, customer or governmental relationships. The VRIN resource characteristics are individually necessary, but not sufficient for a sustained competitive advantage. Grant, Collis and Amit (Grant, 1991; Collis, 1995; Amit \& Schoemaker, 1993) further extended this model where they introduced new factors such as durability, transferability and competitive superiority, which then provided further levels of refinement to the basic model. Empirical research was reported by Collins (200I) where he described the special "characteristics" of successful (great) companies that have enjoyed sustained competitive advantage. He concluded that truly good-to-great companies shared five commonalities, including:

- $\quad$ "Big Personality CEOs almost never lead good companies to greatness" - Good-to-Great leaders have a mix of personal humility and professional will. He described these CEOs as "Level 5 leaders" that continually focus on what it takes to sustain success in the long term.

- "Great things require Great People" -Good-togreat companies got the right people on the "bus" and then built the strategy around the people's expertise and passion. - "Simplicity is Key" - Good-to-Great company's leaders understand the passions of their organizations, the drivers of their business, and where they can be (or not be) the best in the world.

- "Enterprise and Systemic Discipline is essential" When you combine a culture of discipline with the ethics of entrepreneurship you have a recipe to achieve great results. Collins (200I) found that bureaucratic cultures arose in companies that had a lesser degree of competence and lack of discipline.

- "New Technology is a Business Accelerator" Good-to-Great companies do not jump on the technology bandwagon or chase after short-term fads. They determine what technology makes most sense to them and then pioneer novel applications to enhance their business.

Fig. (2) shows the asserted interdependence between a company's strategy and its organizational design, systems, culture, leadership and employee incentives, showing that there are many interlinked factors that must be considered during corporate strategy development.

There are likely many contributing factors that influence a firm's competitive position and it is likely a combination of many VRIN resources and capabilities that will determine the type of company product or service differentiation. Porter's (1979) generic differentiation strategies highlight four possible company strategies that could be 
adopted depending on the type of market and the type of company differentiation. It is necessary for a firm to continuously identify and nurture the VRIN resources and their complementary capabilities to a create product(s) that are continuously attractive in the highest value market segments in order to be successful for the long term.

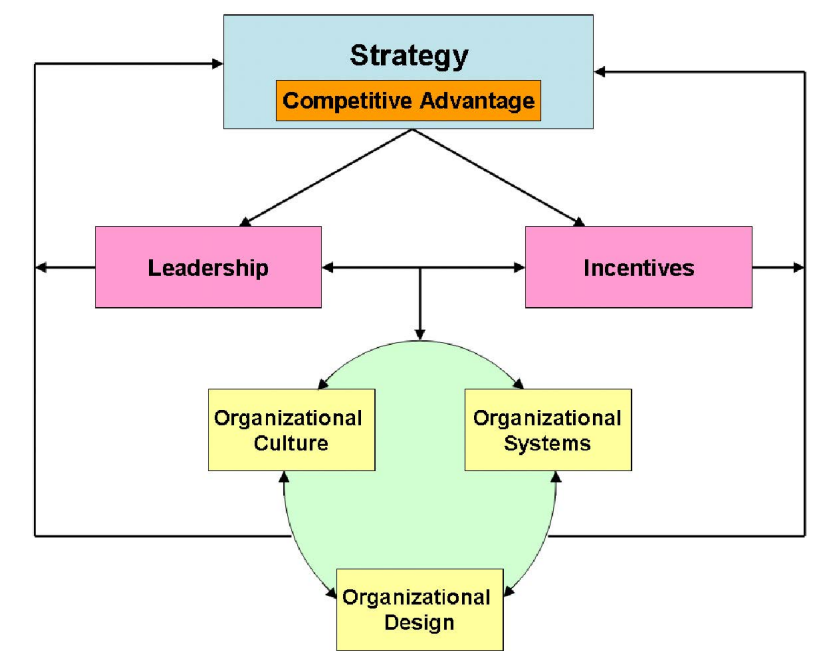

Fig (2) - Interdependence between Company Strategy and Competitive Advantage

Identifying the exact mixture of resources and capabilities that truly provide sustained differentiation is not easy. These are likely embedded deep in the firm, influenced by many things, and will manifest themselves as differentiated products, efficiencies, quality, innovation, or customer service (Hafeez, Zhang \& Malak, 2002). Some of the major organizational levers that are highly likely to influence a company's competitive advantage are:

- $\quad$ Leadership - Company Vision, Mission, Leadership and Governance

- Incentives - Reward and Performance management systems

- $\quad$ Organizational Culture - Corporate Orthodoxies and Values

- Organizational Design - Organizational Structure, Globalization, Collaboration Effects

- Organizational Systems - Strategic Planning, InformationTechnology Infrastructure

These organizational levers represent some of the fundamental control systems that can influence a firm's competitive advantage. However, achieving differential performance on one of these areas will certainly not guarantee sustained success. These elements in turn can be distilled down further to identify the fundamentalVRIN resources or capabilities, which are critical to sustaining a firms' competitive advantage.

\section{Resource Model Factors Analysis}

The major organizational levers that influence a firm's ability to compete successfully will now be discussed, along with historic factors and then augmented by the introduction of more contemporary ideas for optimizing a foundation for a sustained competitive advantage.

\section{Vision, Mission, Leadership and Governance}

It is common for firms to capture and commit their major goals and corporate philosophy in writing as "vision" and "mission" statements (Birnbaum, n.d.). These statements of purpose should describe the firm's fundamental reason for existing, and are typically complementary to a firm's underlying strategy and the represent a powerful message, provided it is compelling, accurate, constantly reinforced and communicated clearly to all levels inside and outside the organization. The mission statement defines the company's current business, its objectives and its approach to reach those objectives by articulating the following:

- $\quad$ Culture: Clearly identify the corporate culture, values, strategy and a view of the future for employees, suppliers and customers;

- Commitment: Address the commitment the firm has to its key stakeholders, including customers, employees, shareholders and the communities in which they serve;

- Objectives: Ensure that the stated company objectives are measurable, the strategy is actionable and the vision is achievable;

- Communication:Try to communicate so that the message is in clear, simple and precise language;

- Engagement: Highly compelling to aid buy-in, engagement and support throughout the organization.

An effective vision/mission statement should resonate with the employees as well as the various constituencies that the firm seeks to influence. A vision/mission statement should represent the organization's fundamental purpose thereby inspiring commitment, innovation and execution. The vision statement should be simple to understand and reflect a realistic, credible and attractive future for the firm that makes employees really want to be part of something this is special and enhancing the possibility that they will be far more creative and engaged.

One of the other major factors behind the continued success or failure of a firm is the quality of leadership at the executive level and throughout the organization. The traits, characteristics and philosophies of good leadership have been widely studied (Morse \& Babcock, 2007) and are fundamental for a leader to truly succeed: 
- Honesty - A leader must display sincerity, integrity and candor.

- Humility - A leader who displays humility has a higher degree of self confidence rises above posturing and political behavior

- Competence -A leader takes actions that are based on reason and moral principles.

- Visionary - A leader sets clear goals and has compelling vision of the future, which highly engages people and appeals to their higher values.

- Inspiring - A leader displays confidence, passion, and mental and physical stamina.

- Intelligence - A leader continuously studies the environment, reflects and seeks new challenges

- $\quad$ Ethical -A leader demonstrates fair treatment to all people.

- $\quad$ Selfless - A leader is always thinking of the company and its long term needs and not making decisions or setting direction that is only good for the resume or for personal gain,

- $\quad$ Broad-minded - A leader seeks diversity of opinions for clarity, innovation and new creative perspectives.

- Courageous - A leader shows perseverance toward the accomplishment of goals, regardless of the seemingly insurmountable obstacles.

- $\quad$ Critical Thinking - A leader uses critical judgment to make good decisions at the appropriate time.

- Imaginative - A leader makes timely and appropriate changes in thinking, plans and methods.

Andersen (2006) discussed that personality characteristics are simply the only foundation for leader, and it is the unique ability to "act" that differentiates a true leader from a follower. For managers and leaders to be successful in any given situation, it is important to understand that a blend of personality, experience, capability, passion, and vision, coupled with the quality of alignment with others in the organization is necessary.

One of the major factors in a company's success is the ability of key employees and managers to face reality through critical thinking, by challenging orthodoxies and looking beyond the obvious for facts that provide insights to the situation that provides deeper meaning. The characteristics of critical thinking are normally associated with a firm's leaders, but it is asserted that a company needs to recruit and actively manage diverse people to widen the degree of critical thinking so it can be more informed about its customers, competitors, markets, stakeholders and the trends that influence their industry.

One final aspect of corporate leadership that can influence the direction of a firm is its corporate governance. Public companies have governance boards, which oversee the com- pany's direction and leadership team. They are accountable to the shareholders and highly important, role in setting direction and providing oversight of a firm (Corporate Governance, n.d.). Specifically they are responsible for:

- Quality of Governance and Ethics - Soundness of the company's strategy, the consistency of the company values, ethics, and the operating effectiveness.

- Validation of Long Term Health - Approval of quality long term investments in physical and intellectual assets

- Competences and Knowledge Base - Tuning corporate skills to present and future opportunities and building a significant knowledge base to support the consistency of results.

- $\quad$ Progress Toward Vision - Progress toward the vision and attainment of milestones based on the strategic plan.

- $\quad$ Auditing of Company Processes - Ensuring that all the necessary business processes are in place, are working effectively and that they support long-term vision and strategic plan.

- $\quad$ Shareholder Value - Defining and monitoring progress toward increased in shareholder value

Based on the responsibilities defined above, a firm's governance board should play a vital role in attaining the long-term company vision and highly influence the ability of a firm to define and sustain its competitive advantage (Erakovic \& Goel, 2008).

\section{Corporate Values and Orthodoxies}

Complementary to a firm's mission and vision, every company has its real "values" that are either written or unwritten and engrained in the culture. Values based management has become visible due to the public corporate scandals that have come to light, e.g. Enron,Worldcom, Tyco and Sunbeam. However, there have been other companies that, without having a corporate scandal as a catalyst, have had leaders who have properly exploited shared values and successfully molded their organizations around these values. Organizational best practices that help reinforce (or even change) corporate values include:

- Managerial Behavior - Corporate leaders at all levels need to demonstrate the chosen values and behaviors

- Leadership- Firms must redesign to change the heart of the organization that sets the standard for the corporate values as this will facilitate change for the remainder of the organization

- $\quad$ Frequency -Communications about the corporate values must be frequent and persistent and be compelling enough for employees to change their behaviors if necessary - Incentives- Processes, information flows, decision rights, and incentive programs must be designed to reinforce the values and desired behaviors. 
- $\quad$ Reinforcement-Employees must truly believe that there are positive consequences to living the values and potentially negative consequences if they adopt opposing behavior.

- $\quad$ Employee Growth- Leaders should hire, grow and promote individuals whose outlook and actions are congruent with the firms underlying values.

Older more established firms have long standing procedures, chosen markets, and other orthodoxies that have evolved over many years, forming part of the corporate culture. These are rarely challenged and are simply accepted as a part of corporate life. On one hand these orthodoxies may be valuable for the firms sustainability on its current course and even considered by many as part of a companies competitive advantage. However, they may also impede new initiatives and should be challenged for value in the context of the current vision, evolving customer needs or in the drive to move the company in a new direction.

Challenging orthodoxies and facilitating strategic thinking are especially valuable if the company is seriously looking at new growth opportunities, beyond simply leveraging its existing product development infrastructure. To facilitate effective strategic thinking, the executive leadership team really needs to view the company as a set of core competences instead of business units with an individual market focus. They should focus on finding new opportunities and leveraging these core competences.

\section{Organizational Design}

Many companies still build their organizations based on a traditional hierarchical departmental model, which facilitates very tight control of the various functional units and can be applied geographically, by product line division or simply by function. This model works best when firms have more predictable, mechanistic business processes and the roles and responsibilities of each department are clear and well defined (Learning Objectives for Organization Design, n.d.). However, in a hierarchy, organization groups will often attempt to maximize output in order to meet or exceed defined metrics, especially when they are directly tied into financial rewards or future opportunities for growth or individual promotion. In this organizational design model there are no explicit incentives for people to work well together. Where the hierarchical model breaks down is when collaboration is fundamentally necessary to achieve common goals.

Structurally, there are several methods of organizing crossfunctional teams (Burgelman, Christensen, \& Wheelwright, 2003), including heavyweight teams that are formed by highly dependant functional groups and lightweight teams that are formed more opportunistically when the need arises. For either type of team to be effective, they should be composed of individuals skilled in their own functional areas and who possess a high degree of mutual respect within the team environment. On the other hand, this matrix organizational setup can also lead to inter-group conflicts as the functional manger can have other priorities and will try to limit the time that his/her people can spend on $\mathrm{x}$-functional projects. Therefore, to achieve effective cross-functional collaboration it is important to have goal alignment.

This can be taken to an even higher level when a mutually successful working partnership has been established with external customers as this allows inter-company teams to collaborate more closely and co-develop new more innovative products together. These new models of organizational design that facilitate innovation and learning require a collaborative sprit to be fully engrained in the culture and systems and are fundamental for both companies to build or sustain a competitive advantage.

One of the key differences in these new organizations is that market and industry analysis becomes the responsibility of people across the organization, not just a select few. Once the value of new opportunities is acknowledged, the realignment process kicks in and resources are rapidly shifted to meet those new challenges. In the case of the networked structure, product development groups in different organizations come together to create solutions that exploit the expertise of the individual groups and so have higher intrinsic value to the end customer. It is essential that the leadership teams focus on also creating a culture that is receptive to change.

Another major consideration in modern organizational design, which impacts a firm's long-term strategy, is globalization. As the pace of globalization continues to increase, firms need to look aggressively for any new opportunities around the world which can augment or even extend the firm's resources or capabilities, e.g. starting a new $R$ and $D$ group levering off skills from a local university or building a new manufacturing plant utilizing a local workforce with a high work ethic. New geographical locations for expansion continue to become attractive as some of the following entry barriers continue to be overcome:

\footnotetext{
- $\quad$ Transportation - Improved transportation of goods and services to new locations,

- Trade Barriers - Increase in "free" trade between countries,

- News and Media - Development of global media provides greater transparency and stability,

- $\quad$ Culture - Blurring of the cultural barriers between countries helps align and clarify values,

- Investment -Increased investment in underdeveloped countries improves infrastructure
} 
- $\quad$ Legal Infrastructure- Easy and flexible operations for corporations due to reduced local bureaucracy and corruption

- eCommerce - Increase in the "connectivity" between the individuals and corporations all over the world.

Extending a firm's business into another country is not easy if there is no solid base to build upon. It requires significant investment in building and supporting the remote operation as well as everyday managerial challenges that can be significant if the team is not well aligned to the needs of the parent organization. This is especially true with small company acquisitions, which already had their own cultural identity. Given this challenge, there are some key issues that must be considered when considering extending the company into another country or remote location, including:

- $\quad$ Leadership: Select a site manager who is skilled in remote site operations and can help facilitate integration and has a good understanding of the corporate systems and needs,

- Communication: Establish strong procedures around communication- phone, e-mail, and video conferencing etiquette and ensure that people adhere to corporate guidelines for sending and replying to email and phone calls. - Systems: Determine how work will be managed and information shared, reviewed, and modified

- Local Culture: Understand how business is really carried out in the new country. Are there are any local customs, religious or other needs from the remote team?

- $\quad$ Language: Put multilingual people in key positions to bridge the language barrier, and make sure the team members know whom they are.

- Social: Facilitate social interactions between remote and local teams to aid in team building

- $\quad$ Technology: Use video conferencing, VOIP, web sharing tools and conference calls extensively.

- Interactions: Facilitate personal communication whenever possible such as face-to-face, over the telephone/ VOIP and visas to the central site(s) to help people understand the bigger picture.

\section{Strategic and Operational Planning}

A firm needs to develop effective strategies in order to grow and be profitable.The strategic planning process is a systemic value creation process that companies should follow to select the most worthwhile strategies that will allow them to deliver on a stated mission and ultimately a high level vision. This strategy requires that firms move away from incremental, tactical thinking and be willing to open new possibilities, specifically: a concerted effort to see the "Bigger Picture" by everyone in the firm, envision many future possibilities and directions, spend the time sorting through vast amounts of data to filter strategic information, seeing patterns, trends and relationships between disparate data, constantly evaluating divergent courses of action for the firm.

Due to the rapid pace of change, one of the key elements of this new model is continuous scanning of industries, technologies and potential markets to select and filter divergent ideas as shown in Fig (3). A firm's vision and mission feed into the strategic planning cycle which reviews divergent market opportunities and industry trends to provide business scenarios which can be analyzed in more depth to determine which ones represent the best opportunities for the firm. These opportunities are finally translated into a prioritized operational plan that is passed down to the respective business and support organizations that build detailed implementation plans with project goals and performance metrics. With this new model of strategic thinking, the probability of error may be greater, but the potential rewards can also be significant if the company can identify a divergent strategy and then tap into a lucrative market early. To facilitate this new process, there are key success factors that can be used make this strategic planning and dialog more effective, these are:

- $\quad$ Leadership Support- Successful strategic planning requires a visible commitment and participation from the company's executives and leaders,

- $\quad$ Define the Process -Seek many people's opinions and thoughts during the planning processes and build a visible system to select and filter divergent ideas.

- $\quad$ Expertise - Plan to use consultants as necessary to help with the process definition, system definition and even to help pull out divergent strategies,

- Effective communication- As always, clear communication is key especially for all those who need to be involved in the strategic planning process, but also let everyone know what is going on and to translate the strategy to have meaning at every level,

- Employee Involvement- Involve as many experienced people as possible in the process to get a diverse set of opinion. Encourage everyone to get involved in industry and market scanning as a matter of everyday business,

- Organizational Planning- Establish an organizational structure and leadership, which will support the move to a more strategically thinking and acting organization.

Transition to this new planning methodology can be difficult, especially for operationally orientated companies, as their culture typically demands concrete data and firm conclusions. They tend to have an "emergency room" mentality where the corporate environment does not encourage spending time on open dialog and discussing divergent views. Also, the pressure on meeting short-term revenue is always present. 


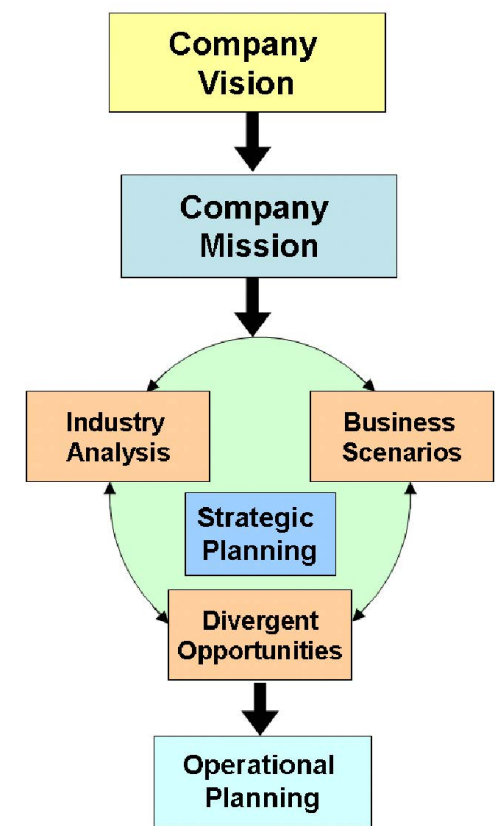

Fig. (3) - Strategic and Operational Planning Cycle

This can limit any efforts to focus energy on change as the top priority is typically to meet the ROI and EPS numbers. The firm's leadership needs to focus on identifying new markets as well as improving the firm's resources and capabilities and leveraging these to enter new divergent markets. If a firm uses its unique resources and capabilities to enter a new market, this will increase the entry barriers for competitors and make these business opportunities more attractive for longer term.

\section{Recruitment and Performance Management}

Human capital management plays a vital part in building a foundation for competitive advantage (Offstein, Gnyawali, \& Cobb, 2005). To have a successful recruitment and performance management process, it is important for the firm's leaders to truly understand underlying employee motivational factors and then build a performance management infrastructure to draw out the best from all employees. The firm's leaders must focus on harnessing the skills and motivation of all employees so that the majority of the workforce can become another key resource that contributes to the company's sustained competitive advantage.

In order to combat competition for highly valued staff, firms may want to be more aggressive and use more contemporary recruitment strategies to attract and retain employees. Some characteristics of a high impact recruitment system should be:

- Proactive Forecasting - Base your recruitment model on pre-need, pre-requisition hiring and integrate your recruitment function with other business critical activities.

- $\quad$ Focusing and Prioritization - Prioritize recruitment needs strategically according to their impact on the bottom line.

- $\quad$ Speed and Agility - Top people are in the market only for a few days, if hiring takes longer you will only be employing the average performers.

- $\quad$ Strategic sourcing - Start research based on anticipated needs. Be highly proactive for critical positions.

- Differentiate the top performers - Refine the ability to filter out unwanted and unqualified candidates early in the process.

- $\quad$ Monitor performance deliverables post-hire - Post hire, track the new hire to ensure they are meeting expectations and how well they are embracing the organization.

- $\quad$ Build a retention-focused culture - Managers can make such a difference in determining whether people stay in a job or leave.

There are more contemporary methods of improving the quality of the recruitment processes, which can help improve the identification of quality candidates with high cognitive abilities including:

- Preparation: Give potential candidates the opportunity to review and prepare a presentation on either a technical or managerial problem.

- $\quad$ Engagement: Involve current employees more in the recruitment process, this is also one way to find out how engaged they are, they may not participate in the interview process significantly, but it makes them feel closer to the decision making and influencing the groups direction.

- Job Options: Move toward offering telecommute, virtual, job sharing or part-time work to tap into a more diverse candidate selection, especially those with long experience who are considering lowering their work hours.

- Web Presence: In today's online world the company web site is one of the primary tools people use to initiate and manage the recruitment process. It is important that the overall style and content reflects the dynamic culture and that directly appeals to the type people that the firm is after. - Publicity: Quality publicity is also important on many levels. Firms should continuously invest in advertising to get the word out using a differential format to attract the right type of professionals.

An effective performance management business process can be critical in the motivation and engagement of employees over the long-run, with more progressive companies considering employee skills improvement, critical thinking, problem solving, cross training, challenging assignments, 360-degree feedback, team feedback, and functional feedback. One fundamental part of the company-employee performance management process-should be the building of mutual trust 
between managers, peers, and subordinates. Increased levels of trust can contribute to more open communication channels and can be a major contributor to an employee's level of discretionary energy.

A more intrinsic factor in employee motivation is the firm's rewards system. Base pay, $40 \mathrm{IK}$, health plans, stock purchase plans and other incentives are commonly used to compensate employees and to drive improvements in performance or help drive through corporate change initiatives. Individual bonus plans that offer incentives for the completion of key projects or behavior change can be a highly effective tool for rewarding and facilitating change (Plunkett, 2007).

Finally there are more specific incentives that a firm can offer which can improve intrinsic motivation at all levels in an organization. These incentives aim for a higher level of satisfaction and motivation through self-actualization (Green \& Burke, 2007) and the attainment of a healthy balance between work and the other aspects of our lives, examples include:

- $\quad$ Personal Activities: Allowing employees to participate in high profile personal, professional or charitable activities even if means giving them some time off work.

- $\quad$ Professional Associations: Encourage and fund involvement in professional or trade associations, you can gain more industrial insight from all levels.

- $\quad$ Cultivate the internal Talent: Offer generous scholarships, funding and organizational rewards for continuing education and offer a periodic sabbatical for long term, highly valued employees to continue their acquisition of knowledge.

- $\quad$ Strategic Incentives: Provide key projects and or cross-functional teams extra financial incentives with bonuses, prizes, and stock.

- Generation of Intellectual Property: Provide generous incentives to generate intellectual property for the firm in the form of papers, patents or trade secrets, etc.

- $\quad$ Team Incentives: Offer more incentives to facilitate deeper camaraderie, teamwork and commitment.

- Visible Awards \& Incentives: Offer awards to all employees at the completion of successful corporate projects, which required a culture or behavior change to attain the goal.

\section{Information Technology Infrastructure}

One of the more recent factors that have become significant in sustaining a competitive advantage is the creation of firm's information technology (IT) infrastructure and extending this beyond the firms IT boundaries into its suppliers and customers (Wong \& Yung, 2005). Such a system is known as an Enterprise Resource Planning (ERP) system and integrates business logistics so that it is more streamlined and accessible as it maintains all the relevant data in a single database and is used for analyzing a variety of business applications such as Manufacturing, Supply Chain Management, Forecasting, Financials, Projects, Human Resources, Supplier Relationship Management (SRM) and Customer Relationship Management (CRM).

The value of the ERP system vs. a more traditional distributed system is that it has a common database and modular software design. The common database allows various corporate functions to utilize information in real-time. This information is reliable, accessible and easily shared. The modular software design allows various departments to select the appropriate modules that they need, mix and match modules from different vendors and also add new modules to improve business performance.A fully integrated ERP system is a powerful tool in managing the business and companies that have evolved their information technology (IT) infrastructure.

It is not easy for most companies to deploy ERP system successfully. The technology itself is difficult to configure and test while changing people's behavior and attitudes toward technology is an even greater challenge (Change Management Perspectives in an ERP Implementation, n.d.). ERP systems typically change jobs specifications in major ways. This type of system is never an easy sell to either the employees or managers as an ERP enables more accountability as it uncovers errors more easily, highlights poor management practices, and shows which employees or managers are the low performers. All employees and managers therefore require higher levels of diligence, accuracy and skills to operate in this IT enabled infrastructure. Firms need to build a company wide enterprise system to retain a competitive advantage. Having a more accurate forecasting system allows companies to adopt Just-in-Time [44] methodologies, which eliminate inventory buildup and make manufacturing processes far more efficient.

ERP systems are primarily associated with improving the supply chain efficiency. However, a more sophisticated system can also be used to support the new product development process by streamlining data access and facilities easy analysis and communication of both internal and external data. Use of more ERP type systems to support innovation and product development is still in its infancy and it is asserted that this will eventually become a cornerstone for the innovation and development processes as modern online ERP based communication tools cut through the organizational boundaries, not only to give people access to real time, customer and internal information, but also extend the tools to allow people to interact in a more personal way through the use of VOIP, personal video cameras, online meeting tools 
and other more interactive discussion boards or Wikki pages. Fundamentally, ERP systems are an attempt at efficient management of real time information, but also can be used to more closely integrate the innovation and product development processes back to the customers, markets and the stakeholder needs. It is paramount for firms to recognize which innovation projects will be of most benefit to the company and so become part of the firm's competitive advantage. ERP systems allow these decisions to be made with higher speed, agility and probability of success.

\section{Methodology and Research Design}

This research has identified and discussed the key organizational levers that have a fundamental influence on the creation of VRIN resources/capabilities and so influence a firm's competitive advantage. In order to quantify a wider perspective on how important these various levers are to a firm's competitive advantage, this exploratory study used an on-line survey prepared using the ClassApps Tool and distributed within National Semiconductor Corporation, a well-established high technology company.

National Semiconductor Corporation (National at a Glance, n.d.) is one of the industry's oldest analog integrated circuit company's and is an ideal candidate to validate many of the key assertions from the paper. It has focused highly on operational excellence throughout its life and over the past 30 years its portfolio has grown to over 3,000 products, including commodity, high performance analog and mixed signal devices and subsystems. National's mixed signal products include power management circuits, display drivers, audio \& operational amplifiers, communication interface products, and data conversion solutions. National's chosen markets include wireless handsets, displays, and a variety of broad electronics markets; including medical, automotive, industrial, and test with measurement applications. National Semiconductor has its headquarters in Santa Clara California and has three wafer fabrication plants, two assembly sites, 40+ design centers, 2,700 patents, employs over 7600 people, and had sales of over $\$ 1.9$ billion in 2007-08.

The major goals of this online survey were (i) to ascertain which of the key assertions made in this paper are widely shared within a typical Hi-Technology company and (ii) the level of importance and (iii) does this importance perspective change depending on the seniority and/or position in the organization. The survey consisted of 33 questions requiring graded or multiple-choice answers. These questions specifically requested quantitative assessment or relative feedback in areas which were previously considered playing an very important role in building or sustaining a firms' competitive advantage:
- Vision \& Mission(Qu\#II) - What aspects of a vision \& mission are compelling enough such that it highly resonates with the work force and engages people to the highest degree,

- Leadership (Qu.\#3) - How important are the firms' leaders to the degree of employee motivation, strategy definition, overall priority and execution efficiency,

- Values and Culture (Qu\#5, 17, 18) - How important are the firms underlying values and the underlying culture in a firms ability to differentiate and/or create or enhance core competences.

- $\quad$ Employees, Engagement and Incentives (Qu\#6, 12) -This factor was considered one of the most important factors on the ability of a firm to drive innovation and execution. But, which specific incentives and factors, e.g. rewards or creative freedom are considered most important to energize people to the highest level

- Organizational Design (Qu\#4) - Modern day organizations have flat managerial hierarchies and employees are now more empowered to make business and strategic decisions. These questions try to ascertain how the organizational design impacts a firm's ability to build or sustain a competitive advantage.

- $\quad$ Corporate Governance and Legal (Qu\#7,9) These questions probe the assertions that the corporate governance board plays a key role in setting the company direction \& the building and sustaining of core competences and also the need for a strong legal team that supports development and defense of a firms IP.

- Operations (Qu\#8) - Operational excellence is know to be fundamental to a firms success, but this question try's to ascertain if the factors that control this are really part of the VRIN competitive advantage of a firm.

- $\quad$ Customer and Market Factors (Qu\#I 0, 29) - These questions seek to quantify the value of having building trust, leading to more receptive customers and eventually to preferential relationships.

- $\quad$ Strategy Development and Alignment (Qu\#I3, I4, $15,16,19,30$ ) - Defining the company direction and chosen markets is so fundamental to success. These questions try to ascertain the value of wide scale participation in strategic planning, strategic marketing teams, translating strategy into context for everyone and the importance of goal alignment. - R\&D Design and Focus (Qu\# 20, 26, 27) - The ability for a firm to harness innovative technology and product ideas and generate new technology is the primary source of competitive advantage. These questions seek opinions on the R\&D methods, optimal organizational approach and the length of commitment for R\&D.

- Recruitment and Performance Management (Qu\#2I, 22) - Recruiting knowledgeable people are perceived to the cornerstone of VRIN type resources and capabilities. These questions assess the value of wide spread critical thinking on innovation and execution and also peer feedback to identify highly valued collaborative people. 
- Information Technology systems (Qu\#24, 25) These questions seek understand the perceived value of a well integrated ERP, IT and information network on a firms competitive advantage.

- $\quad$ Globalization and Partnerships (Qu\#23, 3I) - These questions seek to understand the perceived value of offshore expansion, market globalization and joint ventures \& partnerships on a firm's competitive advantage,.

- VRIN Resources and Capabilities (Qu\#28,32)

- These questions seek to find the most highly valued resources and capabilities relative to others in firm,

The majority of these survey questions were designed to get a graded response to the level of impact of a given factor, i.e. "I" - Not important at all "2" - Mildly important "3" - Important "4" - Highly important "5" - Mission critical. Other questions allowed the participant to identify company strategies and potentialVRIN type resources for a typical Hi-Tech company. The survey was sent to $\sim 250+$ senior managers \&VP's, front line managers and individual contributors in the business units, manufacturing, marketing \& sales, central R\&D, information technology, human resources, legal \& administration organizations.

\section{Results \& Discussion}

The results are based on the $90+$ responses that were received from all organizational levels and groups across the company. All figures and tables are described in Appendix C. Fig (8) shows the functional breakdown of the survey respondents. The majority of the responses were obtained from the business units and the central technology R\&D group which accounted for $60 \%$ of the data, followed by the HR, Legal \& Administration, Marketing \& Sales, Manufacturing and Supply chain services. No further demographic distinctions were made within those sub-groups, except that the participants were allowed to define their functional position. The hierarchical breakdown of respondents is shown in Fig (3), this shows that $40 \%$ came from the individual contributor level, $37 \%$ from the front line managers and $23 \%$ came from Directors, VP's and above.

Tables (I) and (2) are a summary of the top results from each major category as a function of organizational position and job function where the sample sizes were large enough to provide adequate differentiation. More details on the relative preferences are also plotted in Figs. (4) - (9) and indicates which specific aspects of the mission and vision, employee engagement, strategic planning and identification of potential VRIN resources and capabilities have on a firms' competitive advantage.

The data in tables (2), (3) and Fig (6) clearly shows that a firm's ideal vision/mission, i.e. one that will really engage the majority of employees to the highest level, is one based on (i) moving the company toward a compelling new market with a new leadership product and (ii) that can also highly reward both the employees and the firm's leaders. However, the HR, legal and administrative population were the exception to thus and reported that a vision/mission that strived for a higher moral, ethical or a scientific cause would provide the deepest level of engagement from this group.

In the context of incentives, tables (2), (3) and Fig (7) overwhelmingly show that the employee rewards (paycheck, bonus, options) would engage employees to the highest degree regardless of their position and level in the organization. Again, the HR, legal and administrative population, which are not generally so connected with the end-product(s), reported that they as a group would be more engaged if they are allowed to work on the highly compelling projects. This does shows that incentive programs should not be "one-size" fits all and ideally should be highly tailored to the respective functional areas and even to peoples' specific styles and expectations in each organization.

The strategic planning factors were covered in multiple survey questions and the data in tables (2), (3) and Fig (8) summarize the results. This shows that participants believe that firms should primarily focus on finding new markets that highly leverage their existing core competences, however, at a lower priority, firms should also invest for the future and create brand new competences that could open completely new markets. This feedback also highlighted importance that companies should find new and creative ways to engage with customer to obtain preferential relationships.

Tables (2), (3) and Fig (9) gives feedback as to the choice of organizational structure for firms to tackle research and development. The major feedback showed a split preference toward distributed R\&D or x-functional "Tiger" teams driving R\&D projects rather than a well-integrated central $R \& D$ group. However, when the results were filtered via organizational level, all groups believed that a firm's R\&D should be carried out by small-distributed group(s) specializing in their respective areas. In addition, the results in tables (2), (3) and Fig (10), indicate that the optimum level of "creative" free thinking time to help drive innovation was about $10 \%$ with about $20 \%$ of the population feeling that numbers up to $50 \%$ are truly necessary to sustain a competitive advantage. Tables (2), (3) show that survey participants felt that firms should be focusing their primary research based a one to three year completion timeframe, but more senior managers felt that investment for a 5-10 year timeframe was really necessary to sustain a true competitive advantage.

Finally, the survey participants identified the major factors that they believed were the major contributors to a VRIN 
type firms' resources and capabilities. Tables (2), (3) and Fig. (II) gives this feedback. Overwhelmingly, the most valuable IP was considered to be patents, then brand equity, trade secrets, and trademarks. It is notable that patents are always perceived of high value, but in order for these to be truly effective a firm needs to have a good reverse engineering analysis and strong legal teams. However, in this same survey (Fig. I0), a strong legal team was very low on the importance rating, something that is somewhat contradictory to the almost universal assertion that patents should be submitted and aggressively defended.

The overall picture of all the competitive advantage factors is plotted in Fig (10). This is a pareto chart [46] of all the major factors presented in the survey questionnaire. All these factors are aligned with the fundamental assertions made earlier in the paper, however this ordered view now augments this and gives us an indication as to the perceived relative importance of each factor. Overall, from the data scoring $>3$, all the given factors were perceived as "important', but the seven lower tier factors were regarded to have less importance relative to the top seven, which were rated somewhere between "very important" and "mission critical". Specifically these high/low tier factors were:

\section{Highest tier factors (Rating 4.25).}

- The Company's Leadership skills

- $\quad$ Establishing trusted relationships with key custom-

ers

- $\quad$ The company's cultural background and values

- $\quad$ The company's ability to translate the strategy in context at each organizational level

- $\quad$ The company having a solid market reputation

- $\quad$ The need for a strategic market team \& perspec-

tive

- $\quad$ The front line employees are primary factor in a firms competitive advantage

Lowest tier factors (Rating $~ 3.25$ ).

- $\quad$ Need for a strong corporate legal team

- Formal system of peer feedback to improve the performance and alignment of all groups

- $\quad$ Supportive \& accountable governance board

- Globalization as a strategy

- The need to get many diverse inputs in strategy definition

- The need for an ERP system

- The need for higher frequency strategic planning processes

These top seven factors are clearly the major levers behind a company's VRIN resources and capabilities. It is the suc- cessful blending of these high tier factors, which gives rise to the ability for a company to strategize, build new differential competences and execute on novel products that will be successful in the market. However, two of the factors that were highlighted in the survey results that were not addressed in much depth in the earlier literature survey. These were the value of establishing trusted relationships with key customers and the overall market perception. It is acknowledged these are sources of competitive advantage and firms must also work hard to establish trustful, more symbiotic relationships with customers that lead to longer-term partnerships. If these partnerships offer a preferential supplier position in the eyes of the customers, then they too become part of a firm's VRIN resources and capabilities. To establish this level of trust, a firm's sales, marketing organization and IS support infrastructure must create a "high touch" customer support system that aims to establish mutually trusting relationships at the both the engineering and managerial levels.

The survey also offered the recipients the opportunity to provide additional feedback in the area of a firm's market presence and customer relationships, which essentially translate to the "value" a customer places on an inter-company relationship. The feedback was very insightful and is summarized below:

- $\quad$ Competitor \& Industry Knowledge - Build closer relationships and trust with customers to the point where they eventually rely on a firm as being so highly knowledgeable about competitor's best practices and the strengths/ weaknesses of competing products that you become part of their inner circle and part of their decision making processes,

- $\quad$ Reliable Partner -A firm needs to be a partner that can be counted on to help solve unexpected problems that come up in the with the customers' customers,

- Market Presence - A firm's strategy should include marketing and actively selling to as many of the key players in a given market. This magnifies the firm's market presence and creates a perceived leadership position in the eyes of those customers,

- Industry Leadership - A Firm should be visibly committed to a given market for the longer term by constantly evolving new generations of world class products,

- $\quad$ Networked Relationships - A firm needs to invest significant time and energy in building strong-networked relations with the major "decision-makers" at customers at the appropriate level of responsibility.

Further feedback was given in the survey as to potential changes in organizational design, systems or leadership that could influence building or sustaining a firm's competitive advantage. 


\section{Conclusions}

It is essential that similar high-tech firms adopt a more agile and customer centric approach to identifying new markets and future products. To achieve this requires firms require a new level of employee engagement, improved market viability and also an investment in the necessary infrastructure to secure a deeper level of mutual trust with the firm's key customers. Firms will need to take a longer-term perspective in building resources and capabilities that provide the highest entry barriers for competitors. Once attained, these higher levels of trust and differential technology can open up opportunities of maintaining a higher margin business and so securing a sustained competitive advantage.

\section{Future Research}

This study has analyzed many intrinsic factors that influence a company's competitive advantage. The discussions focused on how key organizational levers can be more effectively to build, augment or sustain a firm's core competencies. As an area of future research, it is possible to dive further in each area discussed in the paper in order to gain a deeper understanding of the relative influence of these factors on a firm's ability to remain completive in the longer term. However, due diversity of today's companies, i.e. globalization, multi-cultural companies, pace of technology and new environmental/economic factors, it is unlikely that a qualitative model, no matter how insightful, can be universally applied. However, in a given industry, it would be interesting to build on the study reported in this paper by refining the survey to probe deeper in certain areas to give more insight into the (i) highly valued traits and strategies of a successful leadership team, (ii) success factors in a company's culture that provide agility, innovation and creativity, (ii) success factors for higher trust customer relationships, (iv) development strategies and use of new technology and (v) human capital management factors to highly motivate people within a given industry.

\section{References}

A Brief User Guide to the Creation and use of a SWOT Analysis (n.d.) Coach and Courses. Retrieved from: http:// www.coach-andcourses.com/userimages/SWOTAnalysis. doc

AAKER, D. (1989). Managing Assets and Skills: The Key to Sustainable Competitive Advantage. California Management Review. 3I, 9I-I06.

AMIT, R. \& Schoemaker, P. (1993). Strategic assets and organizational rent. Strategic Management Journal, 14, 33-46.
ANDERSEN, J. (2006). Leadership, personality, and effectiveness. Journal of Socio-Economics, 35, I078-1091.

BARNEY, J. (199I) Firm Resources and Sustained Competitive Advantage. Journal of Management. 17, 99-120.

BIRNBAUM, B. (n.d.). Strategic planning mission - vision values. Retrieved from http://www.birnbaumassociates.com/ mission-vision-values.htm

BOWMAN, C. \& Ambrosini, V. (2003). How the resourcebased and the dynamic capability views of the firm inform corporate-level strategy. British Journal of Management, 14(4), 289-303.

BURGELMAN, R., Christensen, C., Wheelwright, S. (2003). Strategic Management of Technology and Innovation. Location: McGraw-Hill Irwin.

Change management perspectives in an ERP implementation. Retrieved from http://is2.lse.ac.uk/asp/aspecis/20040082.pdf

COLLIS, J. (1995). Competing on resources - A strategy in the 1990's. Harvard Business Review, 73, I I8-1 28.

COLLINS, J. (200I). Good to great. New York, NY: Harper Business.

CORPORATE GOVERNANCE. (n.d.) Retrieved from http:// en.wikipedia.org/wiki/Corporate_governance

DUBOFF, R. (2007). The wisdom of (expert) crowds. Harvard Business Review, 85(9), 28.

ERAKOVIC, L., \& Goel, S. (2008). Board-Management relationships: Resources and internal dynamics. Management Revue, 19(1/2), 53-69.

FAHY J. \& SMITHEE A. (1999) Stategic Marketing and Resource Based View of the Firm.

AMS Review. Retrieved from: http://www.amsreview.org/articles/fahy 10-1999.pdf

GALBRAITH, J. Organizing to deliver solutions. Retrieved from http://www.moderntimesworkplace.com/good_reading/GRLearn/Hybrid.Product.Customer.Org.pdf

GAUTAM R., Barney J., Muhanna W., \& Ray, G. (2004). Capabilities, Business Processes and Competitive Advantage. Strategic Management Journal. 25, 23-37.

GRANT, R. (1991).The Resource-Based Theory of Competitive Advantage: Implications for Strategy Formulation. California Management Review. 33, I I4- 135. 
GREEN, L. \& Burke G. (2007). Beyond self-actualization. Journal of Health \& Human Services Administration, 30, I I6- 128.

HAFEEZ, K., Zhang,Y. \& Malak, N. (2002). Core competence for sustainable competitive advantage: A structural methodology for identification of core competences. IEE Trans Eng Management, 49, 28-35.

HAMEL, G. \& Prahald, C. (1994). Competing for the Future. Location: Harvard Business Press.

KANELLOS, M. Intel replaces some stock options with grants. Retrieved from http://news.cnet.com/Intel-replacessome-stock-options-with-grants/2100-1006_3-5998834. html?tag=nw. 13

KOTTER, J. P. \& Schlesinger, L. A. (2008). Choosing strategies for change. Harvard Business Review, 86, I30-I39.

Learning objectives for organization design. Retrieved from http://jobfunctions.bnet.com/abstract.aspx?docid=7929 I

MAHONY, T. \& Pandin, J. (1992). The Resource Based View Within the Conversation of Strategic Management. Strategic Management Journal. 13, 363-380.

MENKES, J. (2005). Hiring for smarts. Harvard Business Review, I00-II0.

MORSE, L. \& Babcock, D. L. (2007). Managing engineering and technology. (pp. I40-I50). NJ: Prentice Hall Books.

OFFSTEIN, E. H., Gnyawali, D. R., Cobb, A. T.. (2005). A strategic human resource perspective of firm competitive behavior. Human Resource Management Review, 15, 305-319.

PANDEY, I. (2005). Balanced scorecard: myth and reality. The Journal for Decision Makers, 30, 51-66.

PITKETHLY, R. (2006). Oxford Handbook for Strategy-Environmental Analysis. JOURNAL 254-256. Retrieved from: http://scholar.google.com

PLUNKETT, M. (2007). Enhancing executive accountability for behaviors. Organization Development Journal, 25, P8IP84.

PORTER, M. (1979). How Competetive Forces Shape Strategy. Harvard Business Review.

PORTERS 5 FORCES-A Model for Industry Analysis. (n.d.). Quickmba. Retrieved from: http://www.coach-and-courses. com/userimages/SWOTAnalysis.doc
PORTER'S FIVE FORCES Model for Industry Analysis. (n.d.) I00ventures. Retrieved from: http://www. 1000ventures. com/business_guide/mgmt_stategic_ca_byporter.html

PRAHALAD, C. K. \& Hamel, G. et al. (1990). The Core Competence of the Corporation. Harvard Business Review. 3, 7I-79.

Unsure, generic webpage, assuming there's no clear author? Porter's generic strategies. (n.d.). Retrieved from http:// www.quickmba.com/strategy/generic.shtml

RECKLIES, D. (n.d.). Beyond Porter-A Critique of the Critique of Porter. The Manager. Retrieved from: http://www. themanager.org/Strategy/BeyondPorter.htm

SWOT Analysis (n.d.) Wikipedia. Retrieved from: http:// en.wikipedia.org/wiki/SWOT

USEEM, M. (2006). How well run boards make decisions. Harvard Business Review, 84(I I), I30-138.

WERNERFELT, B. (1984) A Resource BasedView of the Firm. Strategic Management

Journal. 5, I7I-I80.

WONG, S.F. \& Yung, K. L. (2005).A new model for ERP assisted partnership development in outsourcing. ICSSSM 2005 International Conference:Vol I:602. 